\title{
OCTAVIO PAZ Y EL CÍRCULO DE LA REVISTA MUNDO NUEVO \\ Jaime Perales Contreras*
}

RESUMEN: El presente ensayo trata sobre la influencia de Octavio Paz como colaborador destacado de publicaciones culturales, en particular, de la revista Mundo Nuevo, fundada por el famoso crítico uruguayo y biógrafo de Jorge Luis Borges, Emir Rodríguez Monegal.

PAlabras Clave: Octavio Paz, revista Mundo Nuevo, Emir Rodríguez Monegal, boom literario, Agencia Central de Inteligencia (CIA).
ABSTRACT: This article showcases Octavio Paz's influence in his role as a distinguished contributor to cultural publications, namely, Mundo Nuevo magazine, created by the famous Uruguayan critic and biographer of Jorge Luis Borges, Emir Rodríguez Monegal.

KEYWORDS: Octavio Paz, Mundo Nuevo magazine, Emir Rodríguez Monegal, The Boom, Central Intelligence Agency (CIA). 
OCTAVIO PAZ Y EL CÍRCULO DE LA REVISTA MUNDO NUEVO*

A Mario Vargas Llosa

$E_{n}$ la década de los sesenta, Octavio Paz estuvo alerta de las publicaciones literarias que aparecieron en América Latina ante el auge de la revolución cubana y lo que se empezaba a prefigurar como la crítica hacia ella por parte de algunos intelectuales, como sería el caso del escritor cubano Guillermo Cabrera Infante, a quien Paz conoció en 1967, en casa de Carlos Fuentes, en Hampstead, Londres. ${ }^{1}$

* El autor agradece a Anna Lee Pauls, Don Skemer y Charles Greene por su apoyo en la Firestone Library, de Princeton University, que me facilitaron el acceso a la correspondencia de Octavio Paz con Emir Rodríguez Monegal. También agradezco al profesor Rafael Landerreche quien me dio acceso a la colección de la revista Mundo Nuevo; parte de ella se encuentra en la biblioteca Manuel Gómez Morín, en el ITAM, cuando colaboré como becario de la biblioteca en la Ciudad de México.
Durante ese período, hubo focos muy pequeños, a veces minúsculos, de revistas literarias que se formaron ante la decadencia de la célebre revista argentina Sur, dirigida por Victoria Ocampo. En ese sentido, Mundo Nuevo fue una publicación importante, pues sirvió de trasfondo cultural para el origen de las revistas de Paz. Mundo Nuevo se fundó en París, en julio de 1966, por el famoso uruguayo Emir Rodríguez Monegal, quien en esas fechas era ya un extraordinario crítico. A los 45 años había producido una obra literaria considerable

${ }^{1}$ Guillermo Cabrera Infante, Todos de alguna forma alrededor de Octavio Paz, en Reforma, Sección cultural El Angel, 25 de marzo de 1994, pp. 1 y 3 . 
como crítico, biógrafo y erudito; a la temprana edad de 15 años había estado dentro del círculo de lectores felices de Jorge Luis Borges. Cuando Monegal estaba dirigiendo la revista Mundo Nuevo, no era poca cosa ser publicado en ella, ya que su reputación era similar a la de Edmund Wilson para las letras angloamericanas. Al hablar de Mundo Nuevo, su publicación literaria aludía a una cultura latinoamericana vital e innovadora, que estaba en el centro de la comunidad internacional. ${ }^{2}$ Por ello, la revista de Monegal se propuso difundir una visión crítica de la nueva literatura latinoamericana. Cuando se estaban empezando los números, le escribió a Octavio Paz una calurosa carta de invitación, fechada el 24 de febrero de 1966, en la que establecía al poeta como el autor intelectual de la nueva revista. Monegal, precisamente, acababa de recibir una carta de Carlos Fuentes, en la que aludía a que Paz y él habían hablado de Mundo Nuevo en Roma. Monegal le recordó que hacía ya muchos años en Nueva York, Paz proyectaba una revista latinoamericana en París. Monegal sugería que considerara a Mundo Nuevo como su revista. Y, además, no necesitaba comentarle que los honraría tener algún material suyo para los primeros nú-

${ }^{2}$ Suzanne Jill Levine, Manuel Puig y la mujer arana, 2002, Barcelona, Seix Barral, 178. meros. ${ }^{3}$ Concretamente, Rodríguez Monegal le pidió un ensayo que no fuera nada académico sobre el escritor nicaragüense Rubén Darío, porque la revista le iba hacer un homenaje en su número de fin de año. Al pobre, según Monegal, lo tenían sepultado las tesis y las polillas y necesitaba algunas páginas que lo renovaran ante la crítica. Paz le mandó su ensayo sobre Darío, el cual aparecería más tarde como parte de su libro Cuadrivio. ${ }^{4} \mathrm{Y}$, precisamente sobre crítica, Monegal le pidió sugerencias y comentarios a su amigo Octavio Paz para que la revista mejorara, ya que Monegal, al igual que Paz, estaban de acuerdo en que se estaba formando una gran, nueva y renovada literatura en América Latina. El reparo principal que tenía Paz de Mundo Nuevo fue que en la revista había mucha ficción, pero carecía de buenos ensayos críticos sobre literatura y política. ¿Cómo podría haber una proyección optimista sobre el futuro de la gran literatura si no se tenía crítica? Octavio Paz, desde hacía tiempo, tenía esa gran preocupación por dicho hueco en la literatura de Hispanoamérica. La literatura moderna, según

${ }^{3}$ Carta de Emir Rodríguez Monegal a Octavio Paz, 24 de febrero de 1966, used by permission of the Princenton University Library.

${ }^{4}$ Carta de Emir Rodríguez Monegal a Octavio Paz, París 23 de mayo de 1966 (Princenton University, used by permission of the Princenton University Library). 
NOTAS

se lo comentaba a Monegal en su carta, era en esencia crítica y vivía de la crítica. Coleridge se alimentaba de Kant, como Góngora de sus mitologías y los poetas franceses vivían y sobrevivían, con la lista más bien ascética de Levi-Strauss y Foucault como parte de una teología. Paz, a la manera de un scholar, le decía a Rodríguez Monegal que la crítica no sólo es el termómetro de la literatura, sino que, en la época moderna, es su condición y fundamento. Los grandes poetas modernos eran para Paz críticos de sí mismos y de la poesía. ¡Había tantos! De Baudelaire y Mallarmé a Michaux y Ponge; de Coleridge a Eliot y Pound; de Pushkin a Mayakovski y Pasternak. Sin embargo, en lengua española, no había habido un solo gran poeta. Existían poetas grandes, y muy grandes, de Darío y Juan Ramón Jiménez a Góngora, Neruda, Vallejo o Huidobro, aunque ninguno de ellos representaba para Paz lo que significaba Mallarmé o cualquier otro de los grandes poetas americanos. De acuerdo con él, en ese tiempo, México había tenido algunos poetas críticos (como Gorostiza y Villaurrutia) pero eran poetas menores o que, verdaderamente, habían callado antes de tiempo. Con el propósito de llenar ese hueco, Paz recién había concluido en esas fechas su famoso ensayo sobre Lévi-Strauss; publicado antes en lengua francesa, le había gustado particularmente al francés. El poeta se lo envió a través de su amigo, el filósofo François Furet. Además, aparte de esa ausencia de crítica, consideraba que la revista de Monegal le daba demasiada importancia al tema del exilio de la literatura latinoamericana en el extranjero. Era un buen negocio, pero no había que perder el sentido de las proporciones. $^{5}$

Monegal le contestó poco más tarde a Paz que sus críticas eran muy acertadas y las suscribía casi completamente. La ausencia total de un crítico de alto nivel era una de sus preocupaciones. Por esa razón, se alegraba de que Paz le hubiese ofrecido un fragmento de su ensayo. El tema del estructuralismo no le había sido indiferente al uruguayo; Severo Sarduy estaba proyectando un número especial de Mundo Nuevo sobre el tema. Pero había dificultad para encontrar material latinoamericano de alto nivel. Era relativamente más fácil hallar textos de creación que de crítica. Agradeció nuevamente y le prometió a Paz tener muy en cuenta todas sus observaciones para ir orientando la revista en un sentido verdaderamente creador. En la carta, se quejó, a propósito de

${ }^{5}$ Carta De Octavio Paz a Emir Rodríguez Monegal, Delhi, 19 de abril de 1967 (Emir Rodríguez Monegal Papers, used by permission of the Princenton University Library). 
la crítica, de Tomás Segovia, que estaba trabajando una nota sobre su libro Cuadrivio. Desesperado de recibirla alguna vez, Monegal decidió ocuparse él mismo del libro, así como de Poesía en movimiento, y concluyó que sería un ensayo muy ambicioso que trataría de situar su obra en una perspectiva lo más amplia posible y de manera actual. ${ }^{6}$

Mientras se publicaba Mundo Nuevo, murió el poeta surrealista André Bretón, buen amigo de Octavio Paz; consternado por la noticia, escribió un texto sobre el poeta, bajo la impresión de su muerte, lo que era para él más un desahogo que otra cosa. Paz no había tenido ni tiempo, ni deseos de reelerlo; sin embargo, le pedía a Monegal que lo publicara en un buen sitio de la revista y en tipo no demasiado pequeño. No lo pedía por él, sino por André Bretón que, para Paz, era todavía muy mal conocido en lengua española. ${ }^{7}$

Más tarde, en una carta fechada y firmada el 15 de noviembre de 1966 por Carlos Fuentes, quien, aparentemente, era la persona que transmitía las noticias sobre las grandes obras de América Latina, Rodríguez Monegal se enteró que Octavio Paz había

${ }^{0}$ Carta de Emir Rodríguez Monegal a Octavio Paz, París 20 de mayo de 1967 (used by permission of the Princenton University Library).

${ }^{7}$ Carta de Octavio Paz a Emir Rodríguez Monegal, Delhi, 6 de octubre de 1966 (used by permission of the Princenton University Library). terminado (o estaba a punto de terminar) un poema muy importante. ¿No se sentía tentado a mandárselo para Mundo Nuevo?, le preguntó campechanamente. El envío de su trabajo sobre Bretón no había servido más que para despertar el apetito, decía Monegal. El poema importante era precisamente el experimento llamado Blanco. $^{8}$

De hecho, Mundo Nuevo fue la revista que también promovió el llamado boom hispanoamericano. Mundo Nuevo trató de utilizar cierta neutralidad cultural al vincular a escritores de distintas ideologías. Sin embargo, no pudo darse esa supuesta neutralidad, ya que hubo una negativa por parte de los intelectuales cubanos -y de escritores cercanos a ellos- a colaborar en la revista. Algunos, incluso, se negaron a publicar sus textos en la revista, como fue el caso de Jorge Edwards, Julio Cortázar y José Lezama Lima, debido al compromiso de ellos con la revolución cubana, como lo hizo notar el mismo Rodríguez Monegal en una reseña para el libro Persona non grata, publicada en la revista Plural de marzo de $1974 .{ }^{9}$ Asimismo, la polarización de las ideas se empezó a entramar de manera compleja cuando en el Congreso del

${ }^{8}$ Carta de Emir Rodríguez Monegal a Octavio Paz, París, 15 de noviembre de 1966 (used by permission of the Princenton University Library).

${ }^{9}$ Emir Rodriguez Monegal, Joseph K. en la Habana, en Plural 39, marzo de 1974, p.78. 
NOTAS

PEN Club, celebrado en Nueva York en 1966, se acusó a Emir Rodríguez Monegal, y de paso a Carlos Fuentes, de estar al servicio del capitalismo internacional. Ya en ese mismo Congreso, los escritores Ignacio Silone y Pablo Neruda habían discutido fuertemente sobre el papel del intelectual en los países del bloque socialista. A pesar del boicot cubano, Mundo Nuevo pudo publicar textos inéditos de creación y crítica de algunos de los más notables escritores latinoamericanos, incluidos Borges, Neruda, Nicanor Parra, Carlos Fuentes, José Donoso, Ernesto Cardenal, Joao Guimaraes Rosa, Leopoldo Marechal, Mario Vargas Llosa, Clarice Lispector, Ernesto Sábato y el propio Octavio Paz. Mundo Nuevo dio a conocer las primicias de algunos libros completamente desconocidos entonces y que serían capitales: Cien años de soledad, de Gabriel Garcia Márquez (dos capítulos: agosto de 1966 y marzo de 1967); Cambio de piel, de Carlos Fuentes (octubre 1966); Tres tristes tigres, de Guillermo Cabrera Infante (tres capítulos: mayo de 1967); Blanco, de Octavio Paz (un fragmento: octubre de 1967); De donde son las cantantes, de Severo Sarduy (noviembre de 1966, octubre de 1967); Los aeropuertos de César Fernández Moreno (junio de 1967); El obsceno pájaro de la noche, de José Dono- so (julio de 1967). ${ }^{10}$ La revista daría excelencia crítica y promoción literaria hasta que Rodríguez Monegal renunciara a la revista en el número 25. La renuncia se debió, sobre todo, a la polarización que se conformaba con respecto a Cuba. Mundo Nuevo era patrocinada por la Fundación Ford; sin embargo, se rumoró que algunos de los ingresos de la Fundación en esa fecha provenían de la Agencia Central de Inteligencia (CIA), mediante una organización llamada Congreso por la Libertad de la Cultura. Algunos intelectuales cubanos acusaron en una carta a Emir Rodríguez Monegal de ser agente de la CIA y de ser propagandista del capitalismo norteamericano. Monegal, preocupado por las críticas y por el boicot cubano, decidió cambiar un poco la política editorial y la orientación de Mundo Nuevo. Le pidió, por ello, su opinión acerca de la revista a Octavio Paz. A pesar de éste, como intelectual, veía con desconfianza cualquier publicación directa, o indirectamente, ligada al Congreso por la Libertad de la Cultura, la revista de Monegal le pareció que había conquistado rápidamente el respeto de los escritores en lengua española. Para Paz, Mundo Nuevo era una de las publicaciones más vivas de Latinoamérica y no le

${ }^{10}$ Emir Rodriguez Monegal, "Notas hacia el boom", en Plural 5,6 y 7, febrero, marzo y abril de 1972. 
parecía cerrada; al contrario, colaboraban en ella casi todos los escritores importantes de las nuevas generaciones hispanoamericanas, los escritores realmente vivos. Asimismo, se hacían comentarios con objetividad y pasión crítica. Para Paz, los términos no eran excluyentes. Le recordó a Baudelaire, para quien la crítica debía ser pasional y abierta hacia el porvenir. Estaban en la revista todos los escritores importantes, con excepción de Cortázar y Lezama Lima. La revista había contribuido, además, a mostrar la realidad y la vitalidad de la nueva literatura latinoamericana. Los comentarios políticos también le parecían casi siempre justos y razonables. Por ello, para Paz era verdaderamente lamentable que la revista cambiase su orientación, porque Rodríguez Monegal había convertido a Mundo Nuevo en un lugar en el que la literatura y la crítica asumían su forma mejor: el diálogo. ${ }^{11}$

Igualmente, con respecto al tema de las aportaciones provenientes de la CIA, Paz contestó que, a su juicio, el problema no residía únicamente en el origen de los fondos, sino que era algo más grave y creía sinceramente que el Congreso por la Libertad de la Cultura (al que Paz no pertenecía porque quería guardar su indepen-

${ }^{11}$ Carta de Octavio Paz a Emir Rodríguez Monegal, París,12 de diciembre de 1967 (used by permission of the Princenton University Library). dencia) había perdido su razón de ser. De acuerdo con él, las ideologías también habían perdido su poder monolítico, con excepción de los Estados Unidos. Para el poeta, era innegable que, en ese tiempo, la política norteamericana era cada vez más belicista e imperialista. No sólo se refería a Vietnam, sino a América Latina; sin embargo, se podía ver que también Paz, como otros intelectuales, dudaba ligeramente del buen nombre de la revista. Él no habría colaborado si Rodríguez Monegal no hubiese sido el director de Mundo Nuevo; además, independientemente de que fuera verdad o no que Mundo Nuevo recibió accidentalmente aportaciones de la CIA por medio de un fondo diferido, Paz se lamentaba precisamente de que esa dependencia económica de la revista -de una institución u organismo-era lo que la hacía verse como cómplice de un crimen que no había cometido. Por ello, con el tiempo, al fundar la suya, tendría más cuidado de no resbalar en el mismo problema que Mundo Nuevo. Para Paz, era una lástima que Mundo Nuevo no pudiera vivir de una manera independiente y desligada de toda acusación internacional norteamericana, inclusive si ésta era efectivamente limpia; aclaraba que su posición no era la de los amigos de la Habana, aunque les daba la razón en muchos puntos. No era posible ni 
NOTAS

deseable suspender las relaciones con los Estados Unidos, sobre todo culturales, aunque había que guardar las distancias. Paz no hubiera colaborado en Mundo Nuevo, si no hubiese sido porque Rodríguez Monegal era el director, y por los amigos, como Tomás Segovia, Severo Sarduy y Carlos Fuentes. ${ }^{12}$

El escándalo de las subvenciones de la CIA se volvió muy difícil para Emir Rodríguez Monegal. Las condiciones básicas para su publicación en Europa iban a ser modificadas y por ello decidió renunciar. Carlos Fuentes le pasó la noticia a Octavio Paz; éste lo sentía y, a su vez, se alegraba porque todos los estúpidos equívocos sobre Monegal desaparecerían. ${ }^{13}$ A Octavio Paz, de hecho, le pareció muy bien que Emir Rodríguez Monegal renunciara a la revista, como muy mal que se intentase presentarlo como agente de la CIA. Su actitud, según Paz, desmentía a sus detractores y desenmascaraba a sus pretendidos protectores. ${ }^{14}$ Severo Sarduy le había entregado al crítico uruguayo un texto de Paz sobre Baudelaire y

${ }^{12}$ Carta de Octavio Paz a Emir Rodríguez Monegal, Nueva Dehli, a 30 de mayo de 1967 (used by permission of the Princenton University Library).

${ }^{13}$ Carta de Octavio Paz a Emir Rodríguez Monegal, Nueva Delhi, a 28 de marzo de 1968 (used by permission of the Princenton University Library).

${ }^{14}$ Octavio Paz y Arnaldo Orfila, Cartas cruzadas, 2005, México, Siglo XXI, pp. 145-196. éste solicitó que se lo devolviese; la única razón que lo animó a colaborar en Mundo Nuevo fue la presencia de Monegal al frente de la revista. De ahora en adelante, aclaró Paz, cesaba su colaboración con la publicación, pues había una serie de equívocos estúpidos en todo el enredo con Mundo Nuevo. Sin embargo, ninguno de los escritores que contaban había dudado de la honradez y honestidad de Monegal. Sobre eso, Paz, según se lo comentó a Monegal, había hablado largamente con Julio Cortázar y su mujer cuando pasaron la temporada en la embajada de México en Nueva Delhi. ${ }^{15}$

La renuncia de Monegal también coincidió con el fracaso de las conversaciones entre Octavio Paz y André Malraux, el novelista francés y Ministro de la Cultura del gobierno de De Gaulle, para patrocinar la revista que tenía en mente Paz. Las conversaciones se promovieron en una coincidencia política, cultural e histórica entre Francia y América Latina. La idea provenía, sobre todo, de la política internacional independiente de De Gaulle. Sin embargo, las gestiones fracasaron, porque Paz vio con anticipación que la intención del Gobierno francés (por medio de su Mi-

${ }^{15}$ Carta de Octavio Paz a Emir Rodríguez Monegal, Nueva Delhi, a 28 de marzo de 1968 (used by permission of the Princenton University Library). 
nisterio de Negocios Extranjeros) era convertir a la revista en un vehículo de propaganda de la cultura francesa, y lo que deseaba el mexicano era una publicación con gustos cosmopolitas, hecha por hispanoamericanos, que fomentara ese entramado cultural entre arte, literatura y política, utilizando la intermediación de un nuevo lenguaje. Por la renuncia de Emir Rodríguez Monegal a Mundo Nuevo, y de la extrema dependencia económica de la revista con la Fundación Ford, le pareció a Paz mucho más necesaria la existencia de una nueva publicación, efectivamente independiente, de América Latina. ${ }^{16}$ El centro de operaciones no fue París, como Mundo Nuevo, o Libre de Juan Goytisolo, sino la Ciudad de México; la revista fue Plural, y su director sería el propio Octavio Paz.

${ }^{16}$ Paz y Orfila, op. cit., p. 145. 
La reproducción total o parcial de este artículo se podrá hacer si el ITAM otorga la autorización previamente por escrito. 